\title{
THE RS1801282 PPARG POLYMORPHISM DEPENDENT METABOLIC EFFECTS OF PIOGLITAZONE IN PATIENTS WITH OBESITY AND CONCOMITANT NAFLD
}

\author{
Vadym Shypulin \\ Department of Internal Medicine No. $1^{1}$ \\ shypulin@me.com \\ Nikolai Rudenko \\ Department of Internal Medicine No. $1^{1}$ \\ dok.don@hotmail.com \\ Oleksandr Martynchuk \\ Department of Internal Medicine No. $1^{1}$ \\ o.martynchuk@ukr.net \\ Aleksandr Koliada \\ Genetics Department \\ Laboratory Diagen \\ 15-A Belorusska str., Kyiv, Ukraine, 04119 \\ alex.genetic@gmail.com \\ Vitaly Guryanov \\ Department of Health Management ${ }^{1}$ \\ i_@ukr.net \\ Nataliia Melnyk \\ Department of Internal Medicine No. $1^{1}$ \\ nataliya.g.melnyk@gmail.com \\ ${ }^{1}$ Bogomolets National Medical University \\ 13 T. Shevchenko blvd., Kyiv, Ukraine, 01601
}

\section{Abstract}

The aim: to investigate the metabolic effects of different treatment options in patients with obesity and concomitant non-alcoholic fatty liver disease (NAFLD) based on the presence of CG and GG genotypes PPARG rs1801282 (Pro12Ala) polymorphism in Ukrainians.

Materials and methods: 123 patients with NAFLD in combination with obesity 1, 2, 3 classes were included in the motivational weight loss program (5 visits, 3 months). The case group was treated with pioglitazone $15 \mathrm{mg} /$ day, while the control group received only a program. Ultrasound steatometry, anthropometric and laboratory tests before and after treatment, genetic testing rs1801282 polymorphism in PPARG gene were performed.

Results: the carriers of CG and GG genotypes PPARG rs1801282 polymorphism had less high stimulated insulin levels compared with groups of different genotypes $(\mathrm{p}<0.001)$. It was found pioglitazone effectiveness with significant difference in dynamics of CAP reduction $(\mathrm{p}<0.001)$ regardless of polymorphism. Dynamics of BMI decrease was the lowest in control group CC carries $-2.81(-3.23 ;-2.39) \mathrm{kg}(\mathrm{p}<0.001)$ compared among other groups. Subjects from pioglitazone group with rs1801282 polymorphism carrying of CG and GG genotypes had significant differences in dynamics of fasting C-peptide decrease, serum uric acid reduction $-1.31(-1.50 ;-1.13) \mu \mathrm{g} / \mathrm{L}$ and $-165.3(-182.80 ;-147.80) \mu \mathrm{mol} / \mathrm{L}(\mathrm{p}<0.001)$ respectively compared among other groups.

Conclusions: Better reduction of metabolic parameters during pioglitazone treatment of patients with obesity and concomitant NAFLD appears to be associated with carrying of CG and GG genotypes PPARG rs1801282 polymorphism.

Keywords: controlled attenuation parameter (CAP), steatometry, HOMA-IR, oral glucose tolerance test (OGTT), serum uric acid. 


\section{Introduction}

Research concerning genetic polymorphisms of obesity and other metabolic risk factors for non-alcoholic fatty liver disease (NAFLD) is a quite popular area in understanding the key factors in the management of NAFLD treatment. Among the most studied polymorphisms common to obesity and NAFLD is the rs1801282 (Pro12Ala) polymorphism in the PPARG (peroxisome proliferator-activated receptor gamma) gene, which is involved in both pathogenesis and treatment $[1,2]$. PPARG2 is known to be most expressed in adipose tissue and macrophages, much less in the liver, skeletal muscle and, also much higher in the placenta. It is 5-10 times higher than the transcriptional activity of PPARG1, which is expressed in most tissues. It is clear that the expression of transcription factors that control fat metabolism is impaired in obese patients and NAFLD. In case of excessive ectopic expression of hepatic PPARG, the formation of triglycerides by the liver is enhanced [3]. Although activation of hepatic-specific PPARGs is steatogenic, treatment of genetically predisposed individuals or NAFLD/NASH induced by diet with PPARG ligands reduces steatosis [4, 5]. Nowadays, recommended for NASH treatment is only one drug - pioglitazone, particularly in T2D where it is registered [6].

The carries of G allele (CG and GG genotypes) Pro12Ala polymorphism in the PPARG gene have reduced lipoprotein lipase activity, leading to an increase in atherogenic low-density lipoproteins cholesterol, very low-density lipoproteins cholesterol, triglycerides, a decrease in high-density lipoproteins cholesterol and higher total cholesterol level while protecting against steatosis [7]. Furthermore, carrying of CG and GG genotypes is associated with a higher body mass index (BMI) and has a protective character for type 2 diabetes (T2D) in persons with less BMI and some features of food eating habits (saturated and/or trans-unsaturated fatty acids). Considering the role of the higher atherogenic coefficient, it is expected the giant numbers of cardiovascular disease events in patients with this phenotype.

Obesogenic environment inviolately leads to NAFLD development [8]. It is well known that an excessive amount of intrahepatic fat is owing by peripheral lipolysis from insulin resistance (IR) due to impaired suppression of lipolysis that is abnormally provoked by stimulated insulin and consequently inhibited oppression of free fatty acid flux in blood plasma after a meal [9]. Moreover, recent studies in animals confirm that serum uric acid vice versa contributes intrahepatic fat accumulation through hyperactivation of the polyol pathway of glucose metabolism [10]. Simultaneously, ferritin influences on glucose metabolism via modulation of secretion $\beta$-pancreatic cells [11]. Passive metabolic traits were not investigated in patients with obesity and concomitant NAFLD based on PPARG rs1801282 polymorphism in Ukrainians. Prior results with inconsistent longitudinal findings of multiple studies of the above-mentioned polymorphism are likely due to pleiotropic effects of PPARG gene and thus different affinity with PPARG agonists.

The aim of this study was to investigate the metabolic effects of different treatment options in patients with obesity and concomitant NAFLD based on the presence of CG and GG genotypes PPARG rs1801282 polymorphism during the treatment with pioglitazone in Ukrainians.

\section{Materials and methods}

The study was conducted at Bogomolets National Medical University, Department of Internal Medicine No. 1 (Kyiv, Ukraine) in accordance with the Declaration of Helsinki and was approved by the Ethic Committee (Ref. No. 122/29.05.2019). The prospective interventional study included 123 Ukrainians who were consulted in 2016-2020. Each patient signed an informed consent to be included in the study. Inclusion criteria: patients diagnosed with obesity using BMI $30-44.99 \mathrm{~kg} / \mathrm{m}^{2}$ in combination with NAFLD (ALT $\leq 2.5$ ULN), determined by ultrasound steatometry (controlled attenuation parameter (CAP) $\geq 2.2 \mathrm{~dB} / \mathrm{cm}$ ), age 18-60 years. Exclusion criteria: hepatitis of different etiologies, type 1 and 2 diabetes, heart failure (NYHA class 2-4), history of bladder cancer in patients and the first line of inheritance, other severe comorbidities. 
By randomization, patients were divided into two groups. All patients were offered a motivational weight loss program consisting of 5 doctor visits over a 3-month follow-up. The program included a modification of the patient's lifestyle: a decrease in the patient's energy diet by $500 \mathrm{kcal}$ from physiological daily energy expenditure and his moderate physical activity of 150-200 min per week (walking at a speed of 5-6 km/h). Self-report adherence and weight loss history with the help of questionnaires were conducted also. All patients underwent genetic testing for the presence rs1801282 polymorphism in the PPARG gene, standard anthropometric measurements, laboratory screening and ultrasound steatometry before and after 3 months of treatment.

Clinical genetic stage of the research involved buccal epithelium sampling and genotype testing. DNA was extracted using AmpliPrime DNA-sorb-AM test system (Next-Bio LLC, Russia). PCR was carried out by ROTOR GENE 6000 analyzer (Corbett, Australia), using the SNP-EXPRESS-SHOT diagnostic kit by Liteh (Russia).

Ultrasound steatometry was used to diagnose NAFLD with a Soneus P7 instrument (Ultrasign, Ukraine). The score of steatosis was determined by the results of US on a scale of CAP, which corresponded to the morphological scale of NAS (NAFLD activity score): light ( $\mathrm{S} 1-2.20-2.29 \mathrm{~dB} / \mathrm{cm})$, moderate $(\mathrm{S} 2-2.30-2.90 \mathrm{~dB} / \mathrm{cm})$, heavy (S3 - more than $2.90 \mathrm{~dB} / \mathrm{cm})[12,13]$.

After 3 months of treatment the dynamics of ultrasound were studied (reduction of liver size, improvement of echostructure, decrease in CAP during treatment).

All patients underwent a $75 \mathrm{~g}$ oral glucose tolerance test (OGTT) according to the recommendations of the World Health Organization [14]. Subjects with a fasting glucose level of at least $7.0 \mathrm{mmol} / \mathrm{L}$ were ineligible for further follow-up testing. Venous blood samples were obtained directly before $(0 \mathrm{~min})$ and during $120 \mathrm{~min}$ the OGTT for determination of plasma glucose and insulin concentrations. Glucose and serum uric acid were measured by the hexokinase glucose-6-phosphate dehydrogenase method and colorimetric assay kit using «Cobas 6000; Roche Diagnostics» (Switzerland), respectively [15]. Insulin concentrations, serum C-peptide, ferritin was determined by immunochemical method with chemiluminescent detection of CLIA on an analyzer «Immulite; Siemens AG» (Germany) [16].

The diagnostic criteria for T2D from the International Diabetes Federation [17] and the World Health Organization [14] were used. The normal type in criteria for T2D was evaluated at less than $6.1 \mathrm{mmol} / \mathrm{L}$ of fasting plasma glucose levels and $7.8 \mathrm{mmol} / \mathrm{L}$ of glucose 120 min levels. Impaired glucose tolerance (IGT) was assessed at less than $6.1 \mathrm{mmol} / \mathrm{L}$ of fasting plasma glucose levels and from $7.8 \mathrm{mmol} / \mathrm{L}$ to $11.0 \mathrm{mmol} / \mathrm{L}$ of glucose $120 \mathrm{~min}$ levels. The T2D was evaluated with a fasting glucose of $7.0 \mathrm{mmol} / \mathrm{L}$ and over or glucose $120 \mathrm{~min}$ of $11.1 \mathrm{mmol} / \mathrm{L}$ and over. The normal ranges were counted up to 25 (acceptable $3-8$ ) $\mathrm{mIU} / \mathrm{L}$ for fasting insulin and 16-166 (acceptable up to 41) mIU/L for stimulated insulin. Fasting C-peptide $-0.8-3.85 \mu \mathrm{g} / \mathrm{L}, \mathrm{C}$-peptide 2 hour after glucose load 3-9 $\mu \mathrm{g} / \mathrm{L}$ took as normal.

Statistical processing of the obtained results was made by using the Statistical Package EZR v. 1.35 (R statistical software version 3.4.3, R Foundation for Statistical Computing, Vienna, Austria) [18]. Shapiro-Wilk test was performed to check the normality of the distribution of the quantitative variables. The median $(\mathrm{Me})$ and the interquartile range $\left(\mathrm{Q}_{\mathrm{I}}-\mathrm{Q}_{\mathrm{III}}\right)$ were calculated for non-normal distributed value. Since some variables did not follow a normal distribution, non-parametric methods were used for the analysis of the data. For the reduction in anthropometric and metabolic parameters the average value $(\bar{X})$ and $95 \% \mathrm{CI}$ was calculated. All statistical tests were based on the two-tailed probability. The null hypothesis was rejected at the significance level of $\mathrm{p}<0.05$. Hardy-Weinberg equilibrium (HWE) online calculator was obtained from https://wpcalc.com/en/equilibrium-hardy-weinberg. Allele frequencies were determined by gene counting. A $\chi^{2}$ test was used to test the HWE. Spearman's rank correlation coefficient was used to estimate the degree of correlation. For the statistical evaluation, the significance of the differences in mean values between the four types was tested by Kruskal-Wallis test followed by Dunn's multiple comparison tests. 


\section{Results}

The clinical characteristics of the study groups are shown in Table 1. There were no significant differences between these two groups in BMI, sex, age, fasting glucose and C-peptide, glucose and insulin $120 \mathrm{~min}$, HOMA-IR Index, ferritin, serum uric acid levels ( $\mathrm{p}>0.05)$. The case group included 61 subjects with an average of fasting insulin $9.76(7.67-12.53) \mathrm{mIU} / \mathrm{L}$ and CAP $2.61(2.47-2.77) \mathrm{dB} / \mathrm{cm}$ levels, the control group consisted of 62 individuals with $10.70(9.59-12.39) \mathrm{mIU} / \mathrm{L}$ and $2.47(2.28-2.69) \mathrm{dB} / \mathrm{cm}$ as an average fasting insulin and CAP levels respectively. The average CAP level was much higher and average fasting insulin levels - less high against such values in the control group. Thus, there were significant differences in fasting insulin and CAP levels before treatment $(p=0.05 ; p=0.02)$ respectively as well as $\mathrm{C}$-peptide $120 \mathrm{~min}$ levels $(\mathrm{p}=0.04)$. Another obtained result indicated the levels of stimulated insulin had a high correlation with serum uric acid $(\mathrm{r}=0.86, \mathrm{p}<0.05)$ and CAP levels $-\mathrm{a}$ medium correlation with HOMA-IR Index $(r=0.60, \mathrm{p}<0.01)$.

At the same time, a significant difference in dynamics of CAP reduction in pioglitazone group compared with control one during treatment $(\mathrm{p}<0.001)$ is represented in Fig. 1.

Table 1

Clinical characteristics of the patients with obesity and concomitant NAFLD before treatment

\begin{tabular}{|c|c|c|c|}
\hline \multirow{2}{*}{ Parameter } & \multicolumn{2}{|c|}{ Me (QI-QIII) } & \multirow{2}{*}{$\mathbf{p}$} \\
\hline & Pioglitazone group $(n=61)$ & Control group $(n=62)$ & \\
\hline $\mathrm{BMI}, \mathrm{kg} / \mathrm{m}^{2}$ & $33.4(31.2-36.0)$ & $32.6(31.4-35.5)$ & 0.53 \\
\hline Sex, male/ female & $29 / 32$ & $35 / 27$ & 0.42 \\
\hline Age, years & $42(35-53.25)$ & $42(34-50)$ & 0.45 \\
\hline Fasting plasma glucose, $\mathrm{mmol} / \mathrm{L}$ & $4.89(4.54-5.40)$ & $5.09(4.63-5.37)$ & 0.59 \\
\hline Plasma glucose $\mathrm{t}=120 \mathrm{~min}, \mathrm{mmol} / \mathrm{L}$ & $5.0(4.70-5.80)$ & $5.1(4.89-5.78)$ & 0.53 \\
\hline Fasting plasma insulin, mIU/L & $9.76(7.67-12.53)$ & $10.70(9.59-12.39)$ & 0.05 \\
\hline Plasma insulin $\mathrm{t}=120 \mathrm{~min}, \mathrm{mIU} / \mathrm{L}$ & $54.89(44.29-69.30)$ & $57.08(39.90-68.19)$ & 0.82 \\
\hline Fasting serum C-peptide, $\mu \mathrm{g} / \mathrm{L}$ & $2.70(2.45-3.06)$ & $2.73(2.52-2.94)$ & 0.97 \\
\hline Serum C-peptide $\mathrm{t}=120 \mathrm{~min}, \mu \mathrm{g} / \mathrm{L}$ & $6.89(5.65-7.93)$ & $7.55(6.41-8.40)$ & 0.04 \\
\hline HOMA-IR Index & $2.78(2.11-3.41)$ & $2.84(2.23-3.29)$ & 0.75 \\
\hline Serum ferritin, $\mu \mathrm{g} / \mathrm{L}$ & $367.70(341.4-384.4)$ & $378.65(361.2-387.0)$ & 0.07 \\
\hline Serum uric acid, $\mu \mathrm{mol} / \mathrm{L}$ & $161.50(109.5-273.0)$ & $170.65(130.1-275.33)$ & 0.65 \\
\hline $\mathrm{CAP}, \mathrm{dB} / \mathrm{cm}$ & $2.61(2.47-2.77)$ & $2.47(2.28-2.69)$ & 0.02 \\
\hline
\end{tabular}

Note: $p$ - level of statistical significance between groups; Me $\left(Q_{I}-Q_{I I I}\right)$ - median value from lower to upper quartile (25 to 75 percentiles). Quantitative variables were compared by the Mann-Whitney test. Qualitative variables were compared by $\chi^{2}$ test

At the start, we confirmed the benefits of pioglitazone treatment on CAP reduction regardless some differences in CAP before treatment.

The distribution of alleles and genotypes in study groups is presented in Table 2. A1leles distribution matched with HWE expectation $\left(\mathrm{p}_{\mathrm{HWE}}=0.09\right)$. Both the distribution of genotypes and alleles had no significant differences $\left(\mathrm{p}_{\mathrm{g}}=0.82 ; \mathrm{p}_{\mathrm{a}}=0.97\right)$.

To manage patients with obesity and concomitant NAFLD we addressed the hypothesis that the influence of primary metabolic parameters during different treatment management on results in groups vary thus may provide more accurate insight to make treatment decision and also dose.

The results of multiple-pairwise comparison procedure in anthropometric and metabolic parameters depending on the presence of PPARG rs1801282 (C>G) polymorphism before treatment and dynamics of treatment are summarized in Table 3, 4. As seen from the foregoing 
Table 3, there were significant differences in carries of $\mathrm{G}$ allele before treatment in fasting insulin $(p<0.001)$ and $C$-peptide levels $(p=0.04)$ compared with carries of CC genotype in case group patients and in insulin $120 \mathrm{~min}$ level $(\mathrm{p}<0.001)$ between groups with different genotypes. Therefore, patients with CG and GG genotypes in case group had much higher fasting insulin and less high stimulated insulin levels, which could be associated with the expression of PPARG gene and activation of related transcriptional factors. Besides, they had basic higher BMI, fasting glucose, less high CAP levels, but the difference was not significant at all 4 groups $(p>0.05)$. There was no significant difference in fasting glucose, C-peptide $120 \mathrm{~min}$ and ferritin levels between groups $(\mathrm{p}>0.05)$. The levels of glucose 120 min were not compared among groups, as there was no T2D in groups or IGT.

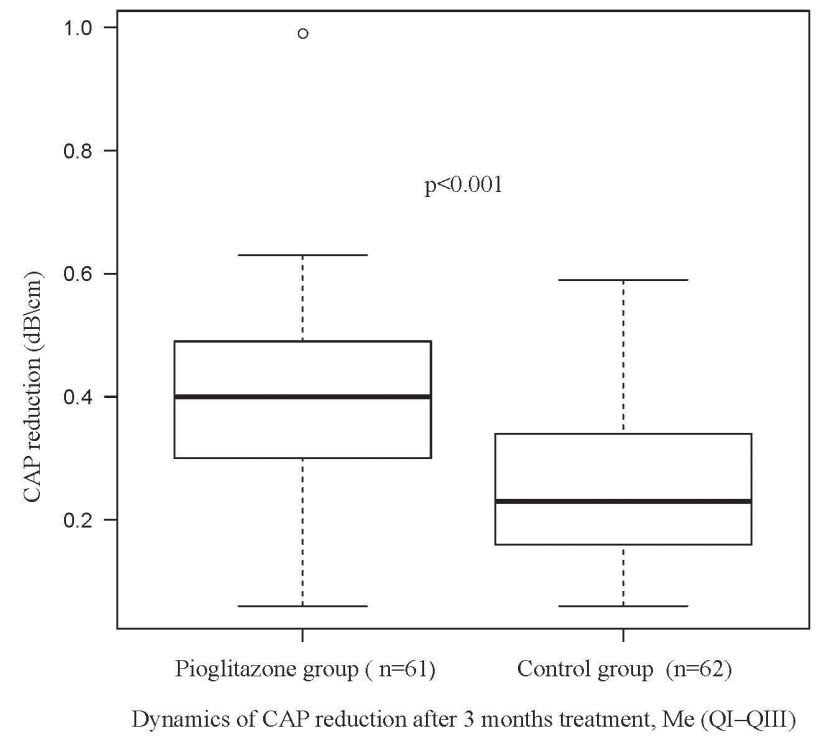

Fig. 1. Dynamics of CAP reduction after 3 months treatment in two groups Me (QI-QIII) - median value from lower to upper quartile (25 to 75 percentiles)

Table 2

The distribution of alleles and genotypes for PPARG rs1801282 (C>G) polymorphism in two groups

\begin{tabular}{|c|c|c|c|c|c|c|}
\hline \multirow{2}{*}{ Variant } & \multicolumn{2}{|c|}{ Pioglitazone group $(n=61)$} & \multicolumn{2}{|c|}{ Control group $(n=62)$} & \multirow{2}{*}{$\mathbf{p}_{\text {HWE }}$} & \multirow{2}{*}{$\mathbf{p}$} \\
\hline & $\mathbf{n}$ & $\%$ & $\mathrm{n}$ & $\%$ & & \\
\hline \multicolumn{7}{|c|}{ Genotypes } \\
\hline $\mathrm{CC}$ & 50 & 81.97 & 51 & 82.26 & \multirow{3}{*}{-} & \multirow{3}{*}{0.82} \\
\hline CG & 10 & 16.39 & 9 & 14.52 & & \\
\hline GG & 1 & 1.64 & 2 & 3.23 & & \\
\hline \multicolumn{7}{|c|}{ Alleles } \\
\hline $\mathrm{C}$ & 110 & 90.16 & 111 & 89.52 & \multirow{2}{*}{0.09} & \multirow{2}{*}{0.97} \\
\hline G & 12 & 9.84 & 13 & 10.48 & & \\
\hline
\end{tabular}

Note: $n$-number; $p_{H W E}$ - the rate of deviation of the allele frequencies from the HWE; $p$-level of statistical significance

As seen from the Table 4, dynamics of decrease were positive in all groups with the most significant difference in case group with CG and GG genotypes in insulin 120 min levels $(\mathrm{p}=0.02)$ compared with control one with CG and GG genotypes and in fasting C-peptide $(\mathrm{p}<0.001)$, serum uric acid levels $(\mathrm{p}<0.001)$ compared with other groups. Interestingly, that there was no significant difference in dynamics of CAP reduction among phenotypes of case 
and control groups with difference regardless of polymorphism $(\mathrm{p}<0.001)$ although BMI decrease was the lowest in control group CC carries $(\mathrm{p}<0.001)$.

Table 3

Results of multiple-pairwise comparison procedure of anthropometric and metabolic parameters depending on the presence of PPARG rs1801282 (C>G) polymorphism before treatment

\begin{tabular}{|c|c|c|c|c|c|}
\hline \multirow[b]{2}{*}{ Parameter } & \multicolumn{4}{|c|}{$\operatorname{Me}\left(Q_{I}-Q_{I I I}\right)$} & \multirow[b]{2}{*}{$\mathbf{p}$} \\
\hline & $\begin{array}{l}\text { Pioglitazone group } \\
\text { with CC genotype } \\
(\mathbf{n}=50)\end{array}$ & $\begin{array}{c}\text { Pioglitazone group } \\
\text { with CG+GG geno- } \\
\text { type }(n=11)\end{array}$ & $\begin{array}{l}\text { Control group with } \\
\text { CC genotype }(n=51)\end{array}$ & $\begin{array}{l}\text { Control group with } \\
\text { CG+GG genotype } \\
(\mathrm{n}=11)\end{array}$ & \\
\hline BMI, $\mathrm{kg} / \mathrm{m}^{2}$ & $\begin{array}{c}33.44 \\
(31.56-35.9)\end{array}$ & $\begin{array}{c}34.57 \\
(30.67-38.38)\end{array}$ & $\begin{array}{c}31.91^{4} \\
(30.93-34.75)\end{array}$ & $\begin{array}{c}36.03^{3} \\
(34.85-41.83)\end{array}$ & 0.02 \\
\hline $\mathrm{CAP}, \mathrm{dB} / \mathrm{cm}$ & $\begin{array}{c}2.65^{4} \\
(2.48-2.78)\end{array}$ & $\begin{array}{c}2.48 \\
(2.28-2.53)\end{array}$ & $\begin{array}{c}2.51 \\
(2.28-2.76)\end{array}$ & $\begin{array}{c}2.34^{1} \\
(2.28-2.45)\end{array}$ & 0.001 \\
\hline $\begin{array}{l}\text { Fasting plasma } \\
\text { glucose, } \mathrm{mmol} / \mathrm{L}\end{array}$ & $\begin{array}{c}4.83 \\
(4.50-5.30)\end{array}$ & $\begin{array}{c}5.40 \\
(4.80-5.55)\end{array}$ & $\begin{array}{c}4.89 \\
(4.61-5.29)\end{array}$ & $\begin{array}{c}5.30 \\
(4.98-5.58)\end{array}$ & 0.14 \\
\hline $\begin{array}{l}\text { Fasting plasma } \\
\text { insulin, } \mathrm{mIU} / \mathrm{L}\end{array}$ & $\begin{array}{c}9.03^{2,4} \\
(7.31-10.66)\end{array}$ & $\begin{array}{c}15.38^{1,3} \\
(11.52-20.10)\end{array}$ & $\begin{array}{c}10.62^{2} \\
(9.55-12.05)\end{array}$ & $\begin{array}{c}14.63^{1} \\
(12.10-16.91)\end{array}$ & $<0.001$ \\
\hline $\begin{array}{l}\text { Plasma insulin } \\
\mathrm{t}=120 \mathrm{~min}, \mathrm{mIU} / \mathrm{L}\end{array}$ & $\begin{array}{c}58.74^{2,4} \\
(45.54-73.25)\end{array}$ & $\begin{array}{c}44.95^{1,3} \\
(30.11-48.02)\end{array}$ & $\begin{array}{c}58.72^{2,4} \\
(51.99-72.97)\end{array}$ & $\begin{array}{c}33.58^{1,3} \\
(25.65-44.14)\end{array}$ & $<0.001$ \\
\hline $\begin{array}{l}\text { Fasting serum } \\
\text { C-peptide, } \mu \mathrm{g} / \mathrm{L}\end{array}$ & $\begin{array}{c}2.69 \\
(2.45-3.0)\end{array}$ & $\begin{array}{c}3.01 \\
(2.44-3.25)\end{array}$ & $\begin{array}{c}2.65^{4} \\
(2.45-2.87)\end{array}$ & $\begin{array}{c}2.97^{3} \\
(2.86-3.59)\end{array}$ & 0.04 \\
\hline $\begin{array}{l}\text { Serum C-peptide } \\
\mathrm{t}=120 \mathrm{~min}, \mu \mathrm{g} / \mathrm{L}\end{array}$ & $\begin{array}{c}7.20 \\
(5.66-7.93)\end{array}$ & $\begin{array}{c}6.80 \\
(4.98-7.75)\end{array}$ & $\begin{array}{c}7.68 \\
(6.44-8.44)\end{array}$ & $\begin{array}{c}7.10 \\
(5.64-7.73)\end{array}$ & 0.07 \\
\hline Serum ferritin, $\mu \mathrm{g} / \mathrm{L}$ & $\begin{array}{c}159.53 \\
(109.00-273.03)\end{array}$ & $\begin{array}{c}206.90 \\
(128.53-325.59)\end{array}$ & $\begin{array}{c}170.77 \\
(124.98-280.30)\end{array}$ & $\begin{array}{c}150.85 \\
(134.32-198.89)\end{array}$ & 0.66 \\
\hline $\begin{array}{l}\text { Serum uric acid, } \\
\mu \mathrm{mol} / \mathrm{L}\end{array}$ & $\begin{array}{c}367.30^{3} \\
(341.37-385.12)\end{array}$ & $\begin{array}{c}367.66 \\
(340.13-383.48)\end{array}$ & $\begin{array}{c}380.77^{1,4} \\
(366.19-397.52)\end{array}$ & $\begin{array}{c}354.27^{3} \\
(326.76-364.07)\end{array}$ & 0.001 \\
\hline
\end{tabular}

Note: $p$-level of statistical significance in difference between the groups; Me (QI-QIII)-median value from lower to upper quartile (25 to 75 percentiles). Nonparametric variables were compared by-Kruskal-Wallis test. Dunn's multiple comparison tests were used for post-hoc test. 1 - significant difference from the pioglitazone group with the CC genotype, $p<0.05$; p2 -significant difference from the pioglitazone group with the $C G$ and $G G$ genotypes, $p<0.05$; $p 3$ - significant difference from the control group with the CC genotype, $p<0.05$; $p 4$ - significant difference from the control group with the CG and GG genotypes, $p<0.05$

Table 4

Results of multiple-pairwise comparison procedure of reduction in anthropometric and metabolic parameters dynamics depending on the presence of PPARG rs1801282 (C>G) polymorphism

\begin{tabular}{|c|c|c|c|c|c|}
\hline \multirow[b]{2}{*}{ Parameter } & \multicolumn{4}{|c|}{$\bar{X}(95 \%$ CI $)$} & \multirow[b]{2}{*}{$\mathbf{p}$} \\
\hline & $\begin{array}{l}\text { Pioglitazone group } \\
\text { with CC genotype } \\
(n=50)\end{array}$ & $\begin{array}{c}\text { Pioglitazone group } \\
\text { with } \mathbf{C G}+\mathbf{G G} \\
\text { genotype }(\mathrm{n}=11)\end{array}$ & $\begin{array}{l}\text { Control group with } \\
\text { CC genotype }(n=51)\end{array}$ & $\begin{array}{c}\text { Control group with } \\
\text { CG+GG genotype } \\
(n=11)\end{array}$ & \\
\hline 1 & 2 & 3 & 4 & 5 & 6 \\
\hline BMI, $\mathrm{kg} / \mathrm{m}^{2}$ & $\begin{array}{c}-4.41^{3} \\
(-4.68 ;-4.14)\end{array}$ & $\begin{array}{c}-5.43^{3} \\
(-6.39 ;-4.47)\end{array}$ & $\begin{array}{c}-2.81^{1,2,4} \\
(-3.23 ;-2.39)\end{array}$ & $\begin{array}{c}-4.43^{3} \\
(-5.40 ;-3.47)\end{array}$ & $<0.001$ \\
\hline $\mathrm{CAP}, \mathrm{dB} / \mathrm{cm}$ & $\begin{array}{c}-0.38^{3,4} \\
(-0.43 ;-0.34)\end{array}$ & $\begin{array}{c}-0.46^{3,4} \\
(-0.536 ;-0.373)\end{array}$ & $\begin{array}{c}-0.27^{1,2} \\
(-0.31 ;-0.24)\end{array}$ & $\begin{array}{c}-0.18^{1,2} \\
(-0.22 ;-0.14)\end{array}$ & $<0.001$ \\
\hline $\begin{array}{l}\text { Fasting plasma } \\
\text { glucose, } \mathrm{mmol} / \mathrm{L}\end{array}$ & $\begin{array}{c}-0.40 \\
(-0.60 ;-0.21)\end{array}$ & $\begin{array}{c}-0.32 \\
(-0.73 ; 0.08)\end{array}$ & $\begin{array}{c}-0.47 \\
(-0.67 ;-0.27)\end{array}$ & $\begin{array}{c}-0.39 \\
(-0.84 ; 0.06)\end{array}$ & 0.95 \\
\hline
\end{tabular}


Continuation of Table 4

\begin{tabular}{|c|c|c|c|c|c|}
\hline 1 & 2 & 3 & 4 & 5 & 6 \\
\hline $\begin{array}{l}\text { Fasting plasma } \\
\text { insulin, } \mathrm{mIU} / \mathrm{L}\end{array}$ & $\begin{array}{c}-2.42^{2,4} \\
(-2.84 ;-2.00)\end{array}$ & $\begin{array}{c}-7.28^{1,3} \\
(-9.16 ;-5.39)\end{array}$ & $\begin{array}{c}-2.60^{2} \\
(-3.05 ;-2.15)\end{array}$ & $\begin{array}{c}-3.56^{1} \\
(-4.14 ;-2.98)\end{array}$ & $<0.001$ \\
\hline $\begin{array}{l}\text { Plasma insulin } \\
\mathrm{t}=120 \mathrm{~min}, \mathrm{mIU} / \mathrm{L}\end{array}$ & $\begin{array}{c}-15.70 \\
(-18.37 ;-13,03)\end{array}$ & $\begin{array}{c}-18.14^{4} \\
(-21.14 ;-15.15)\end{array}$ & $\begin{array}{c}-14.20 \\
(-16.62 ;-11.78)\end{array}$ & $\begin{array}{c}-8.66^{2} \\
(-12.49 ;-4.83)\end{array}$ & 0.02 \\
\hline $\begin{array}{l}\text { Fasting serum } \\
\text { C-peptide, } \mu \mathrm{g} / \mathrm{L}\end{array}$ & $\begin{array}{c}-0.73^{2} \\
(-0.83 ;-0.63)\end{array}$ & $\begin{array}{c}-1.31^{1,3,4} \\
(-1.50 ;-1.13)\end{array}$ & $\begin{array}{c}-0.68^{2} \\
(-0.79 ;-0.57)\end{array}$ & $\begin{array}{c}-0.80^{2} \\
-0.86 ;-0.73)\end{array}$ & $<0.001$ \\
\hline $\begin{array}{l}\text { Serum C-peptide } \\
\mathrm{t}=120 \mathrm{~min}, \mu \mathrm{g} / \mathrm{L}\end{array}$ & $\begin{array}{c}-1.78^{2} \\
(-2.02 ;-1.55)\end{array}$ & $\begin{array}{c}-2.92^{1,3} \\
(-3.56 ;-2.28)\end{array}$ & $\begin{array}{c}-1.74^{2} \\
(-1.99 ;-1.48)\end{array}$ & $\begin{array}{c}-1.78 \\
(-2.01 ;-1.55)\end{array}$ & 0.007 \\
\hline Serum ferritin, $\mu \mathrm{g} / \mathrm{L}$ & $\begin{array}{c}-49.73^{2} \\
(-60.51 ;-38.96)\end{array}$ & $\begin{array}{c}-107.47^{1} \\
(-157.38 ;-57.56)\end{array}$ & $\begin{array}{c}-56.08 \\
(-68.63 ;-43.54)\end{array}$ & $\begin{array}{c}-40.77 \\
(-52.81 ;-28.73)\end{array}$ & 0.03 \\
\hline $\begin{array}{c}\text { Serum uric acid, } \\
\mu \mathrm{mol} / \mathrm{L}\end{array}$ & $\begin{array}{c}-98.49^{2} \\
(-111.67 ;-85.31)\end{array}$ & $\begin{array}{c}-165.30^{1,3,4} \\
(-182.80 ;-147.80)\end{array}$ & $\begin{array}{c}-97.11^{2} \\
(-108.90 ;-85.31)\end{array}$ & $\begin{array}{c}-81.69^{2} \\
(-92.43 ;-70.96)\end{array}$ & $<0.001$ \\
\hline
\end{tabular}

Note: $p$ - level of statistical significance in difference between the groups; $\bar{X}(95 \%$ CI) - the average value of reduction. Nonparametric variables were compared by - Kruskal-Wallis test. Dunn's multiple comparison tests were used for post-hoc test. $p 1$ - significant difference from the pioglitazone group with the CC genotype, $p<0.05$; $p 2$ - significant difference from the pioglitazone group with the CG and GG genotypes, $p<0.05$; $p 3$ - significant difference from the control group with the CC genotype, $p<0.05$; $p 4$ - significant difference from the control group with the $C G$ and $G G$ genotypes, $p<0.05$

\section{Discussion}

Findings from our research demonstrate that in participants undergoing modification of their lifestyles were some significant differences in the average fasting insulin, C-peptide $120 \mathrm{~min}$ and CAP levels before treatment. Features of insulin degradation with short half-life period (3-5 $\mathrm{min}$ ) [19] or secretion type (normal type, insulin-late type, insulin- and glucose-late type, insulin-very late type) as well as binding with peripheral receptors could explain these differences of fasting insulin [20]. Despite knowledge that peripheral C-peptide levels are more accurately reflect portal insulin secretion than measurement of peripheral insulin because of 3-4 times longer half-time life [21], however ranges can vary between laboratories because of lack standardization.

It must be mentioned that less high stimulated insulin level before treatment can be interpreted as fewer IR in carries of CG and GG genotypes. NAFLD patients with rs1801282 polymorphism in case group carries of CG and GG genotypes had significant differences in reduction of insulin 120 min levels $-18.14(-21.14 ;-15.15) \mathrm{mIU} / \mathrm{L}(\mathrm{p}=0.02)$ compared control group such carries. Therefore, it must be mentioned that insulin $120 \mathrm{~min}$ response after treatment with pioglitazone changed greatly in CG and GG genotype patients via presumable modulation of the binding affinity of receptor agonist with PPARG and PPARA. Fasting C-peptide and serum uric acid levels decreased mostly $-1.31(-1.50 ;-1.13) \mu \mathrm{g} / \mathrm{L}$ and $-165.30(-182.80 ;-147.80) \mu \mathrm{mol} / \mathrm{L}(\mathrm{p}<0.001)$ respectively in carries of CG and GG genotypes among all groups. Generally, the case group had significant differences in dynamics of CAP reduction $(\mathrm{p}<0.001)$ regardless of polymorphism as well as the control group carries of CC genotype had the lowest BMI reduction $--2.81(-3.23 ;-2.39) \mathrm{kg}$ $(\mathrm{p}<0.001)$ related to variant gene dependent mechanism.

It was revealed also significant correlation coefficients between CAP levels and HOMA-IR index as well as stimulated insulin levels and serum uric acid levels indicating tight link with metabolic patterns observed. By the way, the reduction of serum uric acid also can help to evaluate decreased IR. The study brought out comprehension of the insulin response to pioglitazone in study groups based on PPARG rs1801282 polymorphism. On the other hand, despite likely widespread opinion about the protection of the G allele Pro12Ala polymorphism PPARG gene against liver steatosis and steatohepatitis [22], we detected higher ferritin levels in carries of this phenotype although without achieving significant differences between groups $(p>0.05)$. Thus, the role of this variant PPARG gene for NAFLD is still unclear [23]. 
Generally, we obtained results that confirmed the effectiveness of pioglitazone on steatosis reduction. Additionally, there are some inconsistent and controversial results after treatment (it is not shown in certain table) and in dynamics based on rs1801282 polymorphism between groups.

Finally, we announced similar findings in some studies but they could not be applicable for all ethnic subgroups [24]. The number of works devoted to this polymorphism had opposite and poor data. Therefore, most authors have not found consistent answers as well.

Study limitations. Nevertheless, our research is not without limitations. We investigated only PCR real-time polymorphism, but it might be interesting to study gene expression levels depending on the allelic variant. Despite the lack of recommendations to use ultrasound steatometry by EASL-EASD-EASO Clinical Practice Guidelines (2016) [6], we assessed the score steatosis without biopsy and NASH grading as we decided it may be insecure and sometimes harmful for patients. However, casual ultrasound is a simple screening method for assessing the presence of steatosis, supplementary measurement of CAP gives more information. In a way if it has been done accurately, steatometry can improve the assessment of steatosis score. Thus, is also reliable and relevant at all.

Prospects for further research. Further compare between groups for finding the reasons of CAP differences before treatment and study the association between the effectiveness of treatment NAFLD with pioglitazone in patients with obesity and PPARG rs1801282 polymorphism is needed.

\section{Conclusions}

Based on the above analysis, the present study demonstrated:

1) PPARG rs1801282 polymorphism carrying of CG and GG genotypes might be associated with less high stimulated insulin level thus IR state;

2) The lowest dynamics of BMI decrease appears to be dependent on CC genotype of control group in contrast of much higher fasting C-peptide and serum uric acid reduction in carries of CG and GG genotypes in case of treatment these groups with pioglitazone;

3) The study has shown better pioglitazone effectiveness in dynamics of CAP reduction regardless of PPARG gene variant, further study of this association with genotype is necessary.

This article is carried out within the framework of scientific research work: «Optimization of Diagnostic and Treatment of Digestive Diseases in Comorbidity Conditions».

\section{Conflict of interest}

The authors declare that they have no conflicts of interest.

\section{References}

[1] Kovalic, A. J., Banerjee, P., Tran, Q. T., Singal, A. K., Satapathy, S. K. (2018). Genetic and Epigenetic Culprits in the Pathogenesis of Nonalcoholic Fatty Liver Disease. Journal of Clinical and Experimental Hepatology, 8 (4), 390-402. doi: http://doi.org/ 10.1016/j.jceh.2018.04.001

[2] Cholankeril, R., Patel, V., Perumpail, B., Yoo, E., Iqbal, U., Sallam, S. et. al. (2018). Anti-Diabetic Medications for the Pharmacologic Management of NAFLD. Diseases, 6 (4), 93. doi: http://doi.org/10.3390/diseases6040093

[3] Wang, N., Kong, R., Luo, H., Xu, X., Lu, J. (2017). Peroxisome Proliferator-Activated Receptors Associated with Nonalcoholic Fatty Liver Disease. PPAR Research, 2017, 1-8. doi: http://doi.org/10.1155/2017/6561701

[4] Lee, Y. K., Park, J. E., Lee, M., Hardwick, J. P. (2018). Hepatic lipid homeostasis by peroxisome proliferator-activated receptor gamma 2. Liver Research, 2 (4), 209-215. doi: http://doi.org/10.1016/j.livres.2018.12.001

[5] Wang, Y., Nakajima, T., Gonzalez, F. J., Tanaka, N. (2020). PPARs as Metabolic Regulators in the Liver: Lessons from Liver-Specific PPAR-Null Mice. International Journal of Molecular Sciences, 21 (6), 2061. doi: http://doi.org/10.3390/ijms21062061

[6] EASL-EASD-EASO Clinical Practice Guidelines for the management of non-alcoholic fatty liver disease. (2016). Journal of Hepatology, 64 (6), 1388-1402. doi: http://doi.org/10.1016/j.jhep.2015.11.004

[7] Wolf Greenstein, A., Majumdar, N., Yang, P., Subbaiah, P. V., Kineman, R. D., Cordoba-Chacon, J. (2017). Hepatocyte-specific, PPAR $\gamma$-regulated mechanisms to promote steatosis in adult mice. Journal of Endocrinology, 232 (1), 107-121. doi: http:// doi.org/10.1530/joe-16-0447

[8] Hall, K. D., Ayuketah, A., Brychta, R., Cai, H., Cassimatis, T., Chen, K. Y. et. al. (2019). Ultra-Processed Diets Cause Excess Calorie Intake and Weight Gain: An Inpatient Randomized Controlled Trial of Ad Libitum Food Intake. Cell Metabolism, 30 (1), 67-77.e3. doi: http://doi.org/10.1016/j.cmet.2019.05.008 
[9] Bugianesi, E., Gastaldelli, A., Vanni, E., Gambino, R., Cassader, M., Baldi, S. et. al. (2005). Insulin resistance in non-diabetic patients with non-alcoholic fatty liver disease: sites and mechanisms. Diabetologia, 48 (4), 634-642. doi: http://doi.org/10.1007/ s00125-005-1682-x

[10] Sanchez-Lozada, L. G., Andres-Hernando, A., Garcia-Arroyo, F. E., Cicerchi, C., Li, N., Kuwabara, M. et. al. (2019). Uric acid activates aldose reductase and the polyol pathway for endogenous fructose and fat production causing development of fatty liver in rats. Journal of Biological Chemistry, 294 (11), 4272-4281. doi: http://doi.org/10.1074/jbc.ra118.006158

[11] Barros, R. K., Cotrim, H. P., Daltro, C. H., Oliveira, Y. A. (2017). Hyperferritinemia in patients with nonalcoholic fatty liver disease. Revista Da Associação Médica Brasileira, 63 (3), 284-289. doi: http://doi.org/10.1590/1806-9282.63.03.284

[12] Marunchyn, N., Dynnyk, B., Kobyliak, N., Fedusenko, A., Barannyk, E. (2017). Attenuation coefficient measurement as novel noninvasive ultrasound method for diagnosis of hepatic steatosis. Endocrinology, 22 (2), 115-120. Available at: https:// endokrynologia.com.ua/index.php/journal/article/view/67/59.

[13] Pu, K., Wang, Y., Bai, S., Wei, H., Zhou, Y., Fan, J., Qiao, L. (2019). Diagnostic accuracy of controlled attenuation parameter (CAP) as a non-invasive test for steatosis in suspected non-alcoholic fatty liver disease: a systematic review and meta-analysis. BMC Gastroenterology, 19 (1). doi: http://doi.org/10.1186/s12876-019-0961-9

[14] World Health Organization (2006). Definition and diagnosis of diabetes mellitus and intermediate hyperglycemia: report of a WHO/IDF Consultation. Available at: http://www.who.int/diabetes/publications/Definition\%20and\%20diagnosis\%20of $\% 20$ diabetes_new.pdf Last accessed: 09.04.2016

[15] Bondar, R. J. L., Mead, D. C. (1974). Evaluation of Glucose-6-Phosphate Dehydrogenase from Leuconostoc mesenteroides in the Hexokinase Method for Determining Glucose in Serum. Clinical Chemistry, 20 (5), 586-590. doi: http://oi.org/10.1093/ clinchem/20.5.586

[16] Albano, J. D. M., Ekins, R. P., Maritz, G., Turner, R. C. (1972). A sensitive, precise radioimmunoassay of serum insulin relying on charcoal separation of bound and free hormone moieties. Acta Endocrinologica, 70 (3), 487-509. doi: http://doi.org/10.1530/ acta.0.0700487

[17] Recommendations for managing type 2 diabetes in primary care (2017). International Diabetes Federation. Available at: www.idf.org/managing-type2-diabetes

[18] Kanda, Y. (2012). Investigation of the freely available easy-to-use software "EZR" for medical statistics. Bone Marrow Transplantation, 48 (3), 452-458. doi: http://doi.org/10.1038/bmt.2012.244

[19] Leighton, E., Sainsbury, C. A., Jones, G. C. (2017). A Practical Review of C-Peptide Testing in Diabetes. Diabetes Therapy, 8 (3), 475-487. doi: http://doi.org/10.1007/s13300-017-0265-4

[20] Takahashi, K., Nakamura, H., Sato, H., Matsuda, H., Takada, K., Tsuji, T. (2018). Four Plasma Glucose and Insulin Responses to a $75 \mathrm{~g}$ OGTT in Healthy Young Japanese Women. Journal of Diabetes Research, 2018, 1-7. doi: http://doi.org/ $10.1155 / 2018 / 5742497$

[21] Jones, A. G., Hattersley, A. T. (2013). The clinical utility of C-peptide measurement in the care of patients with diabetes. Diabetic Medicine, 30 (7), 803-817. doi: http://doi.org/10.1111/dme.12159

[22] Domenici, F. A., Brochado, M. J. F., Martinelli, A. de L. C., Zucoloto, S., da Cunha, S. F. de C., Vannucchi, H. (2013). Peroxisome proliferator-activated receptors alpha and gamma2 polymorphisms in nonalcoholic fatty liver disease: A study in Brazilian patients. Gene, 529 (2), 326-331. doi: http://doi.org/10.1016/j.gene.2013.06.091

[23] Lombardi, R., Pisano, G., Fargion, S. (2016). Role of Serum Uric Acid and Ferritin in the Development and Progression of NAFLD. International Journal of Molecular Sciences, 17 (4), 548. doi: http://doi.org/10.3390/ijms17040548

[24] Black, M. H., Wu, J., Takayanagi, M., Wang, N., Taylor, K. D., Haritunians, T. et. al. (2015). Variation inPPARGIs Associated With Longitudinal Change in Insulin Resistance in Mexican Americans at Risk for Type 2 Diabetes. The Journal of Clinical Endocrinology \& Metabolism, 100 (3), 1187-1195. doi: http://doi.org/10.1210/jc.2014-3246 